\title{
Glial Factors Regulating White Matter Development and Pathologies of the Cerebellum
}

\author{
Miren Revuelta ${ }^{1,2} \cdot$ Till Scheuer $^{1} \cdot$ Li-Jin Chew $^{3} \cdot$ Thomas Schmitz $^{1}$ (])
}

Received: 3 October 2019 / Revised: 7 January 2020 / Accepted: 9 January 2020 / Published online: 23 January 2020

(c) The Author(s) 2020

\begin{abstract}
The cerebellum is a brain region that undergoes extremely dynamic growth during perinatal and postnatal development which is regulated by the proper interaction between glial cells and neurons with a complex concert of growth factors, chemokines, cytokines, neurotransmitters and transcriptions factors. The relevance of cerebellar functions for not only motor performance but also for cognition, emotion, memory and attention is increasingly being recognized and acknowledged. Since perturbed circuitry of cerebro-cerebellar trajectories can play a role in many central nervous system pathologies and thereby contribute to neurological symptoms in distinct neurodevelopmental and neurodegenerative diseases, is it the aim with this mini-review to highlight the pathways of glia-glia interplay being involved. The designs of future treatment strategies may hence be targeted to molecular pathways also playing a role in development and disease of the cerebellum.
\end{abstract}

Keywords Cerebellum $\cdot$ Glia $\cdot$ Development $\cdot$ Pathologies $\cdot$ Therapy

\section{Introduction}

The involvement of the cerebellum in higher processes of cognition and emotion $[1,2]$ and its relevance as a locus for a range of disorders and diseases make this simple yet elusive structure an important model in a number of fields. Cellular and anatomical dysfunction of the cerebellum has been associated with psychological disorders, such as autism, attention deficit, hyperactivity or schizophrenia [3-8]. In recent years, our understanding of some of the more familiar aspects of cerebellar growth, such as its territorial allocation and the origin of its various cell types, has undergone major recalibration. Furthermore, owing to its

Special Issue: In Honor of Professor Vittorio Gallo.

Thomas Schmitz

thomas.schmitz@charite.de

1 Department for Neonatology, Charité University Medical Center, Augustenburger Platz 1, Mittelallee 9, 3353 Berlin, Germany

2 Cellular Oncology Group, Biodonostia Health Research Institute, San Sebastian, Spain

3 Center for Neuroscience Research, Children's Research Institute, Children's National Medical Center, Washington, DC, USA conserved circuitry across species, insights from comparative studies have contributed an increasingly rich picture of how this system develops. During fetal and postnatal development, the cerebellum undergoes dramatic morphological and structural changes, manifested as increased mass and a 30-fold increase of its surface area during the last trimester of pregnancy [9]. The regulation of its complex and dynamic development is driven by glial-glial and glia-neuron interactions, which produce a high variety of factors and molecules for interactive signal transmission [10]. Proliferation and migration of neural progenitor cells in the external granular layer (EGL) as well as the proliferation of immature glial cells are characteristic of late fetal and early postnatal development of the cerebellum. All of these processes are largely influenced or directed by the activity of the Purkinje cells [11-13] together with Bergmann Glia [14-16], by glia-glia [17-19], as well as by glia-neuron interactions [20-22], mainly through signaling via growth factors, chemokines and cytokines, transmitters and transcription factors. This review seeks to highlight shared mechanisms of glial cell regulation that are relevant for development and disease of the cerebellar white matter that may serve to design future strategies for protection. 


\section{Glial Cell Function in Cerebellar White Matter Development}

\section{Astrocytes}

Astrocytes have a central role as supporting cells for neurons and oligodendroglia during brain development. Moreover, they represent a highly reactive cell population in numerous central nervous system (CNS) pathologies. Because of their importance in repair and recovery in neurological diseases, it has been suggested to use stem cell and progenitor cell derived astroglia for cell based therapy, e.g. in patients suffering from stroke, Alzheimer Disease, spinal cord disease, and others [23]. The structural and functional integrity of myelinated axons is critical for their reliable and efficient transmission of information. White matter injury has been associated with the development of many demyelinating diseases. Despite a variety of scientific advances aimed at promoting re-myelination, their benefit has proven at best to be marginal. Research suggests that the failure of the re-myelination process may be the result of an unfavorable microenvironment. Astrocytes are the most abundant and diverse type of glial cell in CNS which regulate cells of the oligodendrocytes lineage in diverse ways. As such, much attention has recently been drawn to astrocyte function in terms of white matter myelin repair. White matter astrocytes are different from those in gray matter in specific regards to development, morphology, location, protein expression and other supportive functions. During the process of demyelination and remyelination, the functions of astrocytes are dynamic in that they are able to change functions in response to distinct stimuli or reactive pathways resulting in vastly different biologic effects. Their effects on oligodendrocytes and other cell types in the oligodendrocyte lineage include: serving as an energy supplier, a participant of immunological and inflammatory functions, a source of trophic factors and iron and a sustainer of homeostasis. As such, the ability to manipulate astrocyte function represents a novel therapeutic approach that can repair the damaged myelin that is known to occur in a variety of white matter-related disorders [23]. The properties of astroglia that are useful for neuroprotection are largely attributed to anti-oxidative properties, stabilization of glutamate homeostasis, and growth factor synthesis. In the cerebellum, astroglial cells are classified into four main groups based on morphology: fibrous astrocytes located in the white matter, stellate multipolar astrocytes or protoplasmic astrocytes located in the granular cell layer, and Bergmann's glia (BG) located between the Purkinje cell layer and the molecular layer and that are specialized astrocytes derived from radial glia (Fig. 1). Developmental roles of astrocytes, particularly involving interactions with neurons, have been the subject of a recent review [24].

\section{Oligodendrocytes}

Oligodendrocytes development is strongly dependent on proper interaction with other types of glial cells, i.e. astroglia

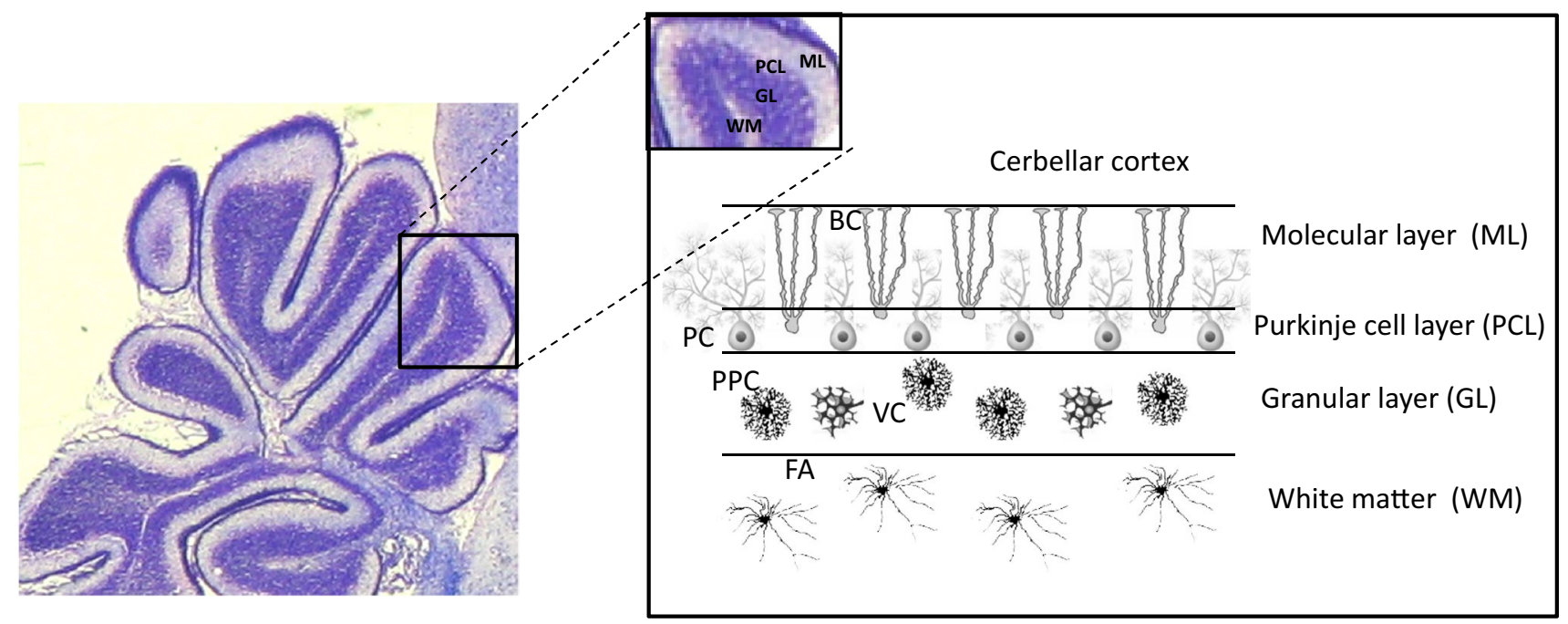

Bergmann glial cell (BC); Purkinje cell (PC); Protoplasmic cell (PPC); Velate cell (VC); Fibrous astrocyte (FA)

Fig. 1 Cell types in the layers of cerebellar folia. $B C$ Bergmann glial cell, $P C$ Purkinje cell, $P P C$ protoplasmic cell, $V C$ velate cell, $F A$ fibrous astrocyte 
and microglia [17]. The establishment of the glial network represents an important step for healthy brain development [25]. Specifically, glial-derived growth factors regulate the survival, proliferation and maturation of glial cells, strongly influence the maturation and development of oligodendrocytes as well as myelination [26-28]. Cell culture experiments show that oligodendroglial cultures in astrocyteconditioned medium survive and proliferate considerably longer than in microglial-conditioned medium [29]. In contrast, microglial-conditioned medium was reported to promote oligodendroglial differentiation and myelination due to its different pattern of cytokines and growth factors in the individual media [29]. The specific composition and the timing of certain cytokine and chemokine signaling appear essential for inducing either proliferation in order to expand the cellular pool during growth or maturation and network establishment (Fig. 2).

\section{Microglia}

Microglia are the cells of the immune system in the CNS that make up about $10 \%$ of the total glial cells within the nervous tissue [30]. In the cerebellum, they distribute over white matter and the cortical layers during development. In the human embryo, colonization of the forebrain with microglia occurs at around 5 gestational weeks, while in rats this event takes place at embryonic day 11 [31]. Ramification as a process of microglial maturation occurs in the human mesencephalon between 11 and 22 gestational weeks, whereas in the cerebellum, the immature ameboid shape remains a predominant microglial phenotype [32]. Cerebellar microglia-Purkinje neuron interactions demonstrate properties distinct from cortical microglia [33]. Recent insight underline a role(s) of microglia for neurite growth, synaptic pruning, spinogenesis, and neuronal apoptosis during brain development [34-36]. Following experimental demyelination in rodents, oligodendrocyte precursor cells (OPCs) proliferate and differentiate into myelin-producing oligodendrocytes which effect robust remyelination. In contrast, remyelination in multiple sclerosis, the major human demyelinating disease, is generally limited and transient. Rodent OPCs have been well characterized in vitro and their response to growth factors documented. Several growth factors known to affect rodent OPCs were tested and found to have similar effects on human cells. PDGF, neurotrophin 3 (NT3), and glial growth factor 2 (GGF2) promoted proliferation, while insulin-like growth factor-1 (IGF-1), exerted a maturational effect [28]. Microglia can induce apoptosis of Purkinje neurons in vitro [37]. In the cerebellum, microglial functionality is needed for the elimination of excess climbing fibers and for proper GABA transmission by Purkinje cells [38].

Microglia has important functions in the maturation and development of oligodendrocytes. They secrete IGF1 and thus support the proliferation and maturation of OPCs [17, 28]. In addition, increased IGF1 stimulation protects immature oligodendroglia against damage triggered by inflammatory processes [29]. Pro-inflammatory, activated microglia interferes with the development of oligodendrocytes. Immature oligodendrocytes and OPCs are vulnerable to inflammatory processes induced by microglia. The survival of immature oligodendroglia and OPCs is reduced by activated microglia. In contrast, survival of mature OLs is enhanced by activated microglia and reduced apoptosis [39].

In the immature brain, exposure to IL $1 \beta$ can cause acute white matter injury [26] and lead to persistent hypomyelination [40]. Microglial contribution to white matter damage via pro-inflammatory responses is also described in models of inflammatory neonatal brain injury and in multiple sclerosis models [41, 42]. IL1 $\beta$ has also been demonstrated to interfere with transmission of GABA and of glutamate in Purkinje cells [43].
Fig. 2 Pathways of glial-neuronal interaction in diseases triggered by inflammation, demonstrated by autism spectrum disorders and ataxia as examples

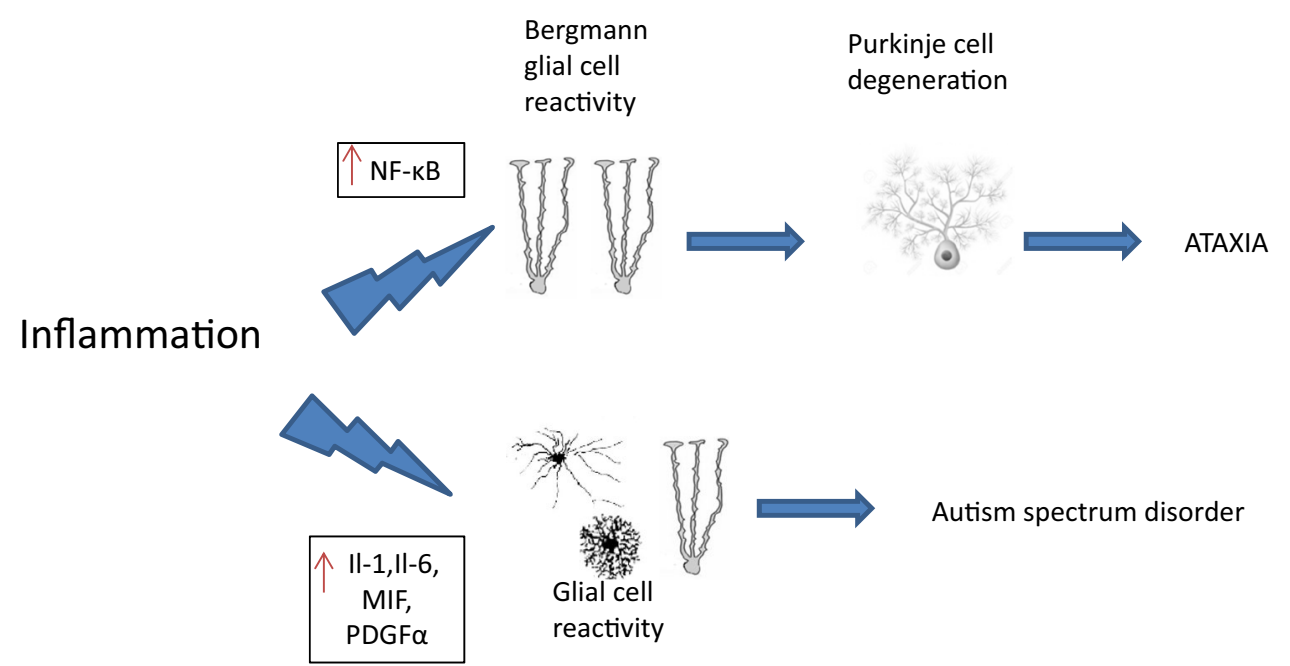


Like neurons, glial cells are also vulnerable to non-physiological glutamate concentrations. All three types of glial cells express different glutamate receptors and transporters. Oligodendrocytes are very sensitive to excessive activity of the glutamate signaling pathway. Microglia is stimulated at elevated glutamate concentrations, leading to the synthesis of inflammatory cytokines. Astrocytes are responsible for glutamate uptake in synaptic and non-synaptic areas and represent the most important regulators of glutamate homeostasis [44]. In addition, they produce $90 \%$ of the brainderived lactate [45], which is an important source of energy for oligodendrocytes during myelination [46].

\section{Cerebellar Pathologies as a Result of Disrupted Glial-Neuronal Interaction}

For brain development, the interaction between glial cells and neurons is essential. This is reflected in the secretion and degradation of neurotransmitters, stimulation by growth factors and also by cell-cell contact, all influencing proliferation, maturation, migration and survival of glial cells and neurons [11, 47-52]. In the developing and also in the adult brain, it has been described that the function of glial cells can influence and regulate neuronal activity [53].

In the development of neurons, astrocytes are assigned an important partner role. In addition to the maintenance of homeostasis by the uptake and breakdown of neurotransmitters [44] and the supply of nutrients to the neurons [54], they are crucially involved in the formation and maturation of synapses [55]. They also support the outgrowth of axons and dendrites as well as the migration of immature neurons [56]. This mutual interaction can be controlled by neurons through the release of growth factors and of neurotransmitters [57].

During development, Bergmann glia, Purkinje cells (PC) and granule cells contribute to the formation of the cerebellar cortex. An average of eight Bergmann glia are in close contact with a PC, thus promoting differentiation, synaptic training, and the transmission of neurotransmitters [58]. The maturation of Bergmann Glia is in turn influenced by PCs: the expression of SHH by Purkinje cells stimulates the maturation and differentiation of the Bergmann glia [59]. In addition, $\mathrm{SHH}$ influences the secretion of gliotransmitters by astrocytes [22] and thus indirectly influences the stimulation of other cell populations by astrocytes.

In agreement with this, ablation of astrocytes and Bergmann glia leads to malalignment of Purkinje cells, and moreover to diminished outgrowth of the dendrites and increased apoptosis of granule cells. $B D N F$, e.g., secreted by astrocytes, is difficult to diffuse over long distances, so local secretion is crucial [60]. Studies have shown that astroglia express both BDNF and the BDNF receptor [19].
BDNF production by Bergmann glia is directly involved in the migration of immature GCs from EGL into the IGL [61].

In addition to astrocytes, microglia also express BDNF during brain development [21]. Microglia of the cerebellum can modulate synaptic circuitry and synaptic activity between GCs and Purkinje cells through the secretion of BDNF [62]. Microglia may exert neuroprotective properties for cerebellar neurons, however, activation of microglia can also be toxic to immature and mature neurons [63].

It has been proposed that synergy between GABAergic synapses and astrocytic processes is limited to Bergmann glia in the cerebellum [64]. Indeed, microglia expresses the GABA B receptor. GABA has a modulating effect on microglia and can attenuate or block their activation with concurrent release of pro-inflammatory cytokines and phagocytic actions [65].

A fundamental and almost symbiotic co-existence of two distinct cell types of the brain can be seen in the intimate interaction between oligodendrocytes and neuronal axons. The formation of a myelin sheath around nerve fibers by oligodendrocytes is critical for an efficient and low-energy stimulus transmission [66]. Electrical transmission itself represents a key signal for oligodendroglia to initiate and enhance the wrapping of axon with myelin [67, 68]. In addition to myelin synthesis, oligodendroglia (OLs) have further influences on the axons of the neurons. It is assumed that OLs provide neurons with additional nutrients via their axons. Inhibition of nutrient transport by oligodendrocytes leads to the degradation of axons and neurons [69].

During development, the interaction of neurons and oligodendrocytes and their precursors plays an important role. Only through contact with an axon is the final maturation of the OLs initiated [66]. Oligodendrocytes express receptors for various neurotransmitters, such as the AMPA receptor [70], the NMDA receptor [71], and GABA A and the GABA $B$ receptor $[51,72]$. The blockade of the release of synaptic vesicles and neurotransmitters leads to impaired myelination [67]. In particular, stimulation with GABA is important for the development of OLs [50,73]. The proliferation, maturation and migration of immature oligodendrocytes is regulated by GABA, in the first postnatal weeks, stimulation with GABA may be crucial for the development of OLs [74].

Decreased myelination has a major impact on the function and maturation of neurons. In a model for the ablation of oligodendrocytes with no myelination, there is a disrupted interaction in the cerebellum between Purkinje cells and the immature progenitors of the granule cells in the EGL. The reduction is also associated with an altered maturation and morphology of PC dendrites [75]. Hence, impairment of one factor relevant to neuron-glia crosstalk may in fact lead to dysregulation of multiple signaling pathways between neurons and glial cells, disrupting development of the cerebellum in multiple ways. 


\section{Cerebellar Glial Cell Alterations in Diseases}

There are many diseases in which glial changes in the cerebellum are involved, such as ataxia, leukoencephalopathy, autism and attention-deficit/hyperactivity disorder (ADHD), multiple sclerosis, as well as hypothyroidism which characteristically involve severe glial dysfunction (Table 1).

\section{Glial Inflammation Disorders}

When glia are activated, inflammation is amplified by the secretion or expression of inflammatory cytokines, chemokines or inducible nitric oxide synthases (iNOS) [76]. The molecules that are released after glial activation, can promote inflammation or exert anti-inflammatory properties. Astrocyte-specific changes analyzed by transcriptomics include decreased cholesterol biosynthesis and increased immune pathway gene expression [77]. Astrocyte cell endfeet contain aquoporin (AQP4) that contributes to regulating the junctional exchange of ions with blood vessels [78]. Among proinflammatory molecules, AQP4 has an important role in controlling brain edema as it is one of the most abundant water channels controlling the water influx in the brain parenchyma [79]. Among anti-inflammatory molecules, TGF $\beta$, responsible of controlling neuroinflammation, is one of the cytokines that is upregulated after glial activation [80] as well as some neurotrophic factors that are release by astrocytes and microglia after an inflammation and are responsible of neuron protection [81].

\section{Multiple Sclerosis (MS)}

AQP4 is one of the most important proinflammatory molecule that is expressed in cerebellum and although its expression level is extremely low in the first postnatal week, it dramatically increases in the second week [82]. In progressive MS, cerebellar lesions frequently present as demyelination in white and gray matter regions [83-85]. Reactive astrocytes are a common feature of MS demyelinating lesions, with observed damage to astrocyte endfeet [86]. In an experimental autoimmune encephalomyelitis (EAE) model relevant to multiple sclerosis (MS), it was observed that the AQP4 increase in the cerebellum is associated with BBB disruption by decreased tight junction proteins, like occludins [87].

In this acute phase of EAE model, in, there is a glutamate-mediated synaptic excitability and neurotoxicity due to the astrocytic release of proinflammatory cytokine interleukin-1 $\beta$ (IL-1 $\beta$ ) $[88,89]$. This systemic cytokine exposure has been linked to hypomyelination and microglial activation in a perinatal inflammation model [90]. Hence, glial interleukin- $1 \beta$ may play a central role in microglial activation and glutamate excitotoxicity in inflammatory diseases of the cerebellum, too.

In a MOG-induced EAE model, increased release of INF $\beta$ by microglia induces demyelination, and increased density of IFN $\beta+$ microglia are found around white matter lesions [91]. As a therapeutic agent, IFN $\beta$ represents a widely used treatment regimen for patients with relapsing-remitting MS (RRMS) [92] and shows treatment efficacy by reducing disease progression and also frequency of exacerbation. In animal experiments, induction of endogenous IFN $\beta$ by polyinosinic:polycytidylic acid [poly(I:C)] treatment

Table 1 Glial cells mechanism in cerebellar development and disease

\begin{tabular}{|c|c|c|}
\hline Glial cells in the cerebellum & Mechanism in celebellar development & Mechanism in disease \\
\hline Astrocytes & $\begin{array}{l}\text { Secrete cytokines and growth factors } \rightarrow \text { oligodendro- } \\
\text { cytes and myelin modulation } \\
\text { Bergmann glia } \rightarrow \text { provides a structure for cerebellar } \\
\text { neuron migration and positioning }\end{array}$ & $\begin{array}{l}\text { Glial inflammation disorders } \\
\mathrm{EAE} \rightarrow \text { proinflammatory cytokine release }(\mathrm{IL}-1 \beta) \\
\mathrm{SCA} 1 \rightarrow \text { Bergmann glial cell reactivity through NF-K } \beta \\
\text { Neuron-glial interaction disorders } \\
\text { ADHD } \rightarrow \text { increased GABA levels } \\
\mathrm{SCA} 7 \rightarrow \text { GLAST function interference, cause Purkinje } \\
\text { cell excitotoxicity } \\
\text { Oxidative stress disorders } \\
\text { Neonatal ischemia } \rightarrow \text { increased } \mathrm{Ca}^{2+} \text { influx in Bergmann } \\
\text { cells }\end{array}$ \\
\hline Oligodendrocytes & $\begin{array}{l}\text { Cerebella cytoarchitecture maintenance } \\
\text { Oligodendrocytes-Neuron interaction maintains and } \\
\text { forms Ranvier nodes and paranodal regions of Purki- } \\
\text { neje cell }\end{array}$ & $\begin{array}{l}\text { Oxidative stress disorders } \\
\text { Postnatal hiperoxia } \rightarrow \text { oligodendroglial maldevelopment } \\
\text { Postnatal hypoxia } \rightarrow \text { hypomielinization and reduced } \\
\text { oligodendroglial maturation }\end{array}$ \\
\hline Microglia & $\begin{array}{l}\text { Regulate neurite growth, synaptic pruning, spinogen- } \\
\text { esis, neuronal apoptosis and oligodendrocyte matura- } \\
\text { tion and development }\end{array}$ & $\begin{array}{l}\text { Inflammation disorders } \\
\text { EAE } \rightarrow \text { increased INF } \beta \text { release } \\
\mathrm{SCA} 1 \rightarrow \text { inflammation (increase of TNFa) } \\
\mathrm{SCA} 3 \rightarrow \text { upregulation of (MMP-2, IL-1 and SDF1alpha) }\end{array}$ \\
\hline
\end{tabular}


diminished the severity of EAE, and genetic deletion of IFN $\beta$ or its receptor in contrast enhanced clinical score, with more extensive CNS inflammation and demyelination [93]. Treament with IFN $\beta$ also reduced axonal damage in a cerebellar slice culture assay with LPS stimulation [94].

\section{Ataxia}

One of the main conditions involving astroglial inflammation of the cerebellum is ataxia or lack of coordination. Ataxia is associated with many neurological conditions, such as stroke, brain tumor, multiple sclerosis, traumatic brain injury, toxicity, infection or congenital cerebellar defects [95]. In particular, spinocerebellar ataxia (SCA) is a group of hereditary ataxias that are characterized by degenerative changes in cerebellum. Mutations in many different genes are known to cause the different types of spinocerebellar ataxias (SCA) [96].

Among the Spinocereberllar ataxias, type 1 (SCA1) is the best known autosomal dominant neurodegenerative disease caused by the abnormal expansion of CAG repeats in the coding region of Ataxin 1 gene [97]. Cvetanovic et al. [98] described astrocytic and microglial activities as an underlying cause of SCA1 which is characterized by the loss of Purkinje neurons in the cerebellum. In that study, Cvetanovic et al. proposed that Bergmann glial cell reactivity signaling through NF-kB, can be responsible for the pathogenesis of Purkinje cell during SCA1, because of their location and intimate interaction [99]. Furthermore Ferro et al. [97] found that the inhibition of NF- $\mathrm{kB}$ in microglia of SCA1 decreased the density of microglia and TNF $\alpha$ expression.

In spinocerebellar ataxia type 3 (SCA3), in which abnormal CAG repeats are localized in the coding region of a gene encoding ataxin-3, there is upregulation of matrix metalloproteinase 2 (MMP-2), interleukin-1 and the cytokine stromal cell-derived factor 1alpha (SDF1alpha) due to astroglial and microglial inflammation [100], causing abnormalities in the Purkinje cell. Recently, it has been suggested that antisense oligonucleotides (ASOs) may serve as a potential therapy technique for SCA3 [101].

\section{Autism Spectrum Disorder}

A psychiatric pattern that seems to be related to glial cell inflammation in the cerebellum is described in autism spectrum disorders (ASD), which begin during early childhood development and are influenced by genetic and environmental factors. The cerebellum has been described to be a brain region of particular relevance for ASD, and for some of the characteristical symptoms of the disorder. It has been suggested that cerebro-cerebellar connectivity is aberrant in ASD patients [102,103]. Available research studies suggest that chronic neuroinflammation may represent a substantial pathogenic influence in the disease. Altered expression of proinflammatory cytokines and chemokines, such as IL-1, IL-6, macrophage migration inhibitory factor (MIF) and platelet derived growth factor (PDGF) has been demonstrated in ASD patients in the peripheral blood or in brain tissues [104]. The relevance of systemic inflammation for ASD symptoms is also revealed by successful treatment of children with diagnosis of ASD using autologous stem cell infusions, which resulted not only in impressive reduction of symptoms [105] but also in reduction of serum cytokine levels [106]. Dysregulated inflammatory activity in glial cells of the CNS, and specifically in the cerebellum, may therefore represent a therapeutic target in ASD.

\section{Neuron-Glia Interaction Disorders}

The role of neuron-glia interaction in neurodegenerative disorders still remains unknown. The cerebellum, due to its simple anatomical organization and well-characterized circuitry, can be a useful tool to approach disorders of neuron-glial interactions [107].

Attention-deficit/hyperactivity disorder (ADHD) is a behavioral and developmental neurological disorder characterized by motor hyperactivity and loss of impulse control, combined with attention deficits and hampered academic performance [108]. A link to cerebellar pathologies has been revealed in clinical studies showing decreased cerebellar volume during in ADHD patients [109]. In G protein-coupled receptor kinase-Interacting protein-1 (GIP1) knockout mice, a genetically modified ADHD model, there is a decrease in GABA levels in astrocytes of the cerebellum that enhances the excitatory/inhibitory input ratio, leading to motor hyperactivity in ADHD. However the mechanism of GABA reduction is still unknown $[110,111]$.

Spinocerebellar ataxia type 7 (SCA7) is an autosomal dominant inherited neurodegenerative disorder with a polyglutamine (polyQ) expanded protein in the nuclear inclusions, and CAG trinucleotide repeats in the coding region of Ataxin-7 [112]. Indeed, it has been identified that polyQ expanded ataxin-7 interfered with the function of GLAST, a glia-specific glutamate transporter which is highly expressed in Bergmann glia, causing Purkinje cell excitotoxicity [106].

\section{Oxidative Stress in Cerebellar Glial Cells}

Cerebellar damage in very immature infants can range from the subtle-generalized delay of tissue development and maturation in response to oxidative stress and/or systemic perinatal inflammation, - to severe-bleeding after rupture of the immature vessels, hence leading to focal lesions and parenchymal cysts as sequel. In a newborn rodent model, the great vulnerability of the immature cerebellum in response to oxidative stress has been characterized by maturational 
delay in oligodendroglial lineage cells, hypomyelination, and inflammatory changes in microglia [113].

\section{Ischemia}

After brain ischemia, as a response to inflammation, there is a generation of reactive oxygen species (ROS) in the neonatal and adult brain. Among the many ROS producers, the most important ones seem to be the NADPH oxidase (NOX) as the main superoxide producer [114], Xanthine oxidase (XO), that contributes to brain edema, and the intracellular enzymes such as COX lipoxygenases (LOXs), and cytochrome $\mathrm{P} 450$ that are involved in the arachidonic acid metabolism, a major superoxide source during ischemic stroke in the brain [76]. Moreover, the mitochondrial electron transporter chain is another important ROS source in the neonatal and adult brain. During reperfusion after ischemia, a massive increase of intracellular $\mathrm{Ca} 2+$ influx may be induced, and $\mathrm{Ca} 2+$ accumulation in the mitochondria can provoke free radical production, impairment in mitochondrial membrane permeability and inhibition of ATP production [115]. Particularly in the cerebellum, during oxygen glucose deprivation (OGD), anoxic depolarization of Purkinje cell in cerebellar slices invokes glutamate release from AMPA receptor activation. Indeed, this glutamate release has been proposed to be regulated by glial $\mathrm{pH}$ changes [116]. Moreover, after OGD, Bergmann glial cells, increased intracellular $\mathrm{Ca} 2+$ influx and membrane depolarization due to the increase of extracellular $\mathrm{K}+$ concentration with the outflow of anions through DIDS sensitive channels [117].

\section{Postnatal Hyperoxia}

In utero, arterial oxygen tension is maintained at low levels but premature birth can provoke an increase in arterial oxygen tension upon exposure to the ex utero environment [118]. Scheuer et al. in 2015 found increased levels of nitrotyrosine in the cerebellar lysates correlated to cerebellar volume deficit, increases apoptosis in oligodendroglia precursor cells (OPCs) and a significant in vivo reduction of astroglial PDGF $\alpha$, BDNF, FGF2 that may contribute to oligodendroglial maldevelopment. After hyperoxia, ultrastructure analysis by electron microscopy indicated thinning of the myelin sheath around the axon. In those experiments, markedly reduced PDGF-A expression was found in the cerebellum. The reduction of PDGF-A expression by high oxygen levels was confirmed in purified astrocyte cultures in vitro, suggesting the impairment of astroglia-oligodendroglia-crosstalk as a cause of cerebellar injury [118]. However, astroglial morphology and GFAP expression were not affected by hyperoxia. Consistent with delayed maturation of microglia in the cerebellum, most of the Iba1 microglia in the cerebellar white matter were of ameboid morphology in postnatal rats cerebella under control and hyperoxia conditions. There were otherwise no obvious hyperoxia-induced changes in morphology or antigen presentation in microglia in the cerebelli of hyperoxia animals.

There are certain compounds that can also induce oxidative stress in the cerebellum, such as Phytanic acid (3,7,11,15-tetramethylhexadecanoic acid, Phyt). Phyt is a chlorophyll derived acid that is obtained from daily products, such as milk, cheese or red meat. The accumulation of this fatty acid provokes many peroxisome disorders. Particularly in the cerebellum, it can induce histopathological abnormalities, including Purkinje cells alteration with a cellular loss and delayed dendrite development and astrogliosis due to the disruption of redox homeostasis. Indeed, in a mouse model of Phyt intracerebellar administration reactive nitrogen species were increased [119], indicating the potential risks to cerebellar integrity.

\section{Postnatal Hypoxia}

In a perinatal brain injury model, the application of chronic hypoxia within the first weeks of postnatal development leads to hypomyelination of the subcortical white matter [120]. Oligodendroglial damage has also been described in the cerebellum; altered development of the cerebellar white matter after chronic hypoxia has been described to be caused, at least partially, by the loss of GABAA receptormediated synaptic input to cerebellar OPCs, which enhances OPC proliferation and reduces oligodendroglial maturation and myelin synthesis [73].

\section{Targets for Potential Therapy}

Brain diseases often involve inadequate homeostasis in neuronal and glial cells. In astroglia, pathogenic changes can be found in diverse processes e.g., glutamate uptake, neurotrophins, growth factors, transcription factors, antioxidative capacity, transmitters, as aforementioned. Consequently, these factors and pathways are offering treatment opportunities via prevention of toxicity or via activation of mechanisms of protection and repair.

\section{Inflammation Regulation}

$\mathrm{NF}-\mathrm{\kappa B}$ is a key transcription factor implicated in neuroinflammation which may mediate events in cerebellar astrogliosis. Indeed, during inflammation NF- $\mathrm{KB}$ is activated and IKK is phosphorylated [121]. This activation produces neurotoxic and inflammatory molecules that lead to different diseases. With regard to SCA1, one of the main diseases related to astroglial inflammation in the cerebellum, it has 
been suggested that NF- $\mathrm{\kappa B}$ signaling is stage dependent and the activity in SCA1 and the of NF- $\mathrm{kB}$ occurs only in the last stages of the SCA1 [121]. Moreover, Kim and co-workers [99] performed selective inhibition of NF- $\mathrm{KB}$ in astroglial cells, which in early stages has in fact increased motor deficits, higher Purkinje cell pathology and increased microglial density. With inhibition in late stages however, SCA1 motor deficits are ameliorated, accompanied by better rotarod performance and decreased microglial density. Interestingly, GFAP expression was decreased during the inhibition of $N F-\kappa B$ in early stages while it was increased in late stages, indicating that astroglial NF- $\mathrm{KB}$ pathway is beneficial during early, pre-syntomatic stage of the disease and it's inhibition during late stage has also beneficial outcomes in SCA1 desease [121].

\section{Minocycline}

Neuroprotective properties of this antibiotic have been demonstrated in different brain injury models, including hypoxia-ischemia [122-124] perinatal inflammation/infection [125] and hyperoxia [113]. The mechanisms by which minocycline exerts its benefits have largely been ascribed to inhibition of microglia. In the immature brain, inhibition of microglia may in fact perturb neuronal development and survival [126]. Toxic effects have been reported to vary with species, i.e. in mice, minocycline enhances brain injury caused by hypoxia-ischemia [127]. Extensive safety tests are therefore required. In an oxidative stress challenge, protection by minocycline coincided with attenuation of oxidative stress and of apoptotic cell death [113], which is supporting previous results on anti-oxidant and anti-apoptotic effects of this drug [128].

\section{Oxidative Stress Modulation}

Glutamate neurotoxicity is directly associated with ROS production and consequently to oxidative stress [129, 130]. The Amburana cearensis, a species of the family of Fabaceae, has been observed to have antioxidant properties in the cerebellum that increase the levels of glutathione reductase and glutathione peroxidase enzyme. These control the intracellular signaling cascade of glutamate exitotoxicity that stimulates calcium influx and mitochondrial dysfunction, minimizing glial and neuronal cell death. In cerebellum astrocyte-derived cell culture, Amburana cearensis antioxidant compounds increase glutamine synthetase activity, which reduces glutamate neurotoxicity in astrocytes. Another compound important for redox balance in the cerebellum is the docosahexaenoic acid (DHA), the most abundant $\mathrm{n}-3$ fatty acid in the brain derived from fish. DHA is essential for normal brain function and astrocytes are responsible for DHA synthesis $[131,132]$. Indeed, it has been recently suggested that supplementation with DHA can be an effective treatment against spinocerebellar ataxia 38 (SCA38) a syndrome characterized by the mutation in the ELOVL5 gene that encodes an elongase enzyme responsible for very low chain fatty acids in the cerebellum [133].

\section{Growth Factors}

The protection of cerebellar white matter development by minocycline was associated with improved PDGF-A expression in vivo and in astrocyte cultures in vitro, underlining a role for astroglial PDGF-A both in injury and protection in the cerebellum. Administration of PDGF-A intranasally after exposure to oxygen challenge moreover resulted in enhanced proliferation of oligodendroglial lineage cells in the cerebellar white matter [134], hence strengthening the view of growth factor synthesis as a target for protective treatment after postnatal insult.

In the chronic hypoxia model of white matter damage in the immature brain, overexpression of the human the receptor of epidermal growth factor (EGF) in oligodendroglial lineage cells after injury attenuates oligodendroglia cell death, increases the generation of new oligodendroglia from progenitors, and initiates recovery [135]. Moreover, intranasal administration of heparin-binding EGF during recovery after exposure to hypoxia enhanced OPC pool and oligodendroglial maturation, and also diminished ultrastructural pathologies and behavioural deficits. Hence, targeting the EGF receptor in oligodendrocyte progenitor cells during a certain time window is potentially beneficial for treatment of preterm infants with white matter damage. Nonetheless, these investigations were performed in the cerebrum/forebrain, a similar therapeutic effect of EGF administration on oligodendroglial maturation during postnatal development can be assumed to occur in the cerebellum, too.

\section{GABA Modulation}

Balancing excitatory and inhibitory synaptic transmission is necessary for a proper brain function. Indeed, one of the main inhibitory neurotransmitter is the c-Aminobutyric acid (GABA) involved in neural tissue development. It has been suggested that mice treated with GABAA receptor antagonist mimics hypoxia effects, so the blockade of GABA uptake reduces NG2 progenitor cell numbers and increases the formation of mature oligodendrocyte $[73,136]$. Recently Woo et al. [137] suggested that the manipulation of the levels of astrocytic tonic GABA in the cerebellum and in particular, in Bergmann glial cell, modulates neuronal excitability and synaptic transmission in the cerebellum. Moreover, the pharmacological inhibition of Bestrophin 1 (Best1), a protein that inhibit GABA release in Bergmann glial cells and the inhibition of mitochondrial enzyme monoamine oxidase 
B (MAOB), a protein in charge of GABA synthesis in astrocytes, causes an increased neuronal excitability in cerebellar granule cells, synaptic transmission and motor performance on the rotarod test. Conversely, increased astrocytic GABA release resulted in reduced motor activity, indicating that the astrocytes are a key component modulating GABA function and consequently modulating motor activity [137].

\section{Conclusions}

The cerebellum is a brain region that is involved in many complex brain functions such as coordination, cognition, memory, emotion. In several neurodevelopmental and neurodegenerative diseases, damage of the cerebellum contributes to overall neurological symptoms. Given the fundamental role of glial cell types and glia-glia interactions for development, disease, and repair in the cerebellum, it is reasonable to target specific properties and functions of these cells for therapeutic purposes. For future investigations, growth factors like PDGFA and EGF, homeostasis of transmitters such as GABA and glutamate, various anti-oxidants and inflammatory modulators altogether represent a promising list of candidates that may serve for cerebellar protection.

Acknowledgements Open Access funding provided by Projekt DEAL. Funding was provided by Deutsche Forschungsgemeinschaft (Grant Nos. SCHM3007/3-2 and SCHE2078/2-1), Institute of Education, University and Research of the Basque Government (Grant No. POS_2017_1_0095) and Förderverein für Frühgeborene Kinder an der Charité e.V.

Open Access This article is licensed under a Creative Commons Attribution 4.0 International License, which permits use, sharing, adaptation, distribution and reproduction in any medium or format, as long as you give appropriate credit to the original author(s) and the source, provide a link to the Creative Commons licence, and indicate if changes were made. The images or other third party material in this article are included in the article's Creative Commons licence, unless indicated otherwise in a credit line to the material. If material is not included in the article's Creative Commons licence and your intended use is not permitted by statutory regulation or exceeds the permitted use, you will need to obtain permission directly from the copyright holder. To view a copy of this licence, visit http://creativecommons.org/licenses/by/4.0/.

\section{References}

1. Koziol LF, Budding D, Andreasen N et al (2014) Consensus paper: the cerebellum's role in movement and cognition. Cerebellum 13:151-177. https://doi.org/10.1007/s12311-013-0511-x

2. Adamaszek M, D'Agata F, Ferrucci R et al (2016) Consensus paper: cerebellum and emotion. Cereb Lond Engl. https://doi. org/10.1007/s12311-016-0815-8

3. Smith REW, Avery JA, Wallace GL et al (2019) Sex differences in resting-state functional connectivity of the cerebellum in autism spectrum disorder. Front Hum Neurosci 13:104. https:// doi.org/10.3389/fnhum.2019.00104
4. Winkler M, Biswas S, Berger SM et al (2019) Pianp deficiency links GABAB receptor signaling and hippocampal and cerebellar neuronal cell composition to autism-like behavior. Mol Psychiatry. https://doi.org/10.1038/s41380-019-0519-9

5. Berquin PC, Giedd JN, Jacobsen LK et al (1998) Cerebellum in attention-deficit hyperactivity disorder: a morphometric MRI study. Neurology 50:1087-1093

6. Ito M (2006) Cerebellar circuitry as a neuronal machine. Prog Neurobiol 78:272-303. https://doi.org/10.1016/j.pneur obio.2006.02.006

7. Botellero VL, Skranes J, Bjuland KJ et al (2016) Mental health and cerebellar volume during adolescence in very-low-birthweight infants: a longitudinal study. Child Adolesc Psychiatry Ment Health 10:6. https://doi.org/10.1186/s13034-016-0093-8

8. de Castro-Manglano P, Mechelli A, Soutullo C et al (2011) Structural brain abnormalities in first-episode psychosis: differences between affective psychoses and schizophrenia and relationship to clinical outcome: volume changes in first affective psychoses. Bipolar Disord 13:545-555. https://doi.org/10.111 1/j.1399-5618.2011.00953.x

9. Volpe JJ (2009) Cerebellum of the premature infant: rapidly developing, vulnerable, clinically important. J Child Neurol 24:1085-1104. https://doi.org/10.1177/0883073809338067

10. Meier F, Giesert F, Delic S et al (2014) FGF/FGFR2 signaling regulates the generation and correct positioning of Bergmann glia cells in the developing mouse cerebellum. PLoS ONE 9:e101124. https://doi.org/10.1371/journal.pone.0101124

11. Fleming JT, He W, Hao C et al (2013) The Purkinje neuron acts as a central regulator of spatially and functionally distinct cerebellar precursors. Dev Cell 27:278-292. https://doi. org/10.1016/j.devcel.2013.10.008

12. Kapfhammer JP (2004) Cellular and molecular control of dendritic growth and development of cerebellar Purkinje cells. Prog Histochem Cytochem 39:131-182

13. White JJ, Sillitoe RV (2013) Development of the cerebellum: from gene expression patterns to circuit maps. Wiley Interdiscip Rev Dev Biol 2:149-164. https://doi.org/10.1002/wdev.65

14. Cheng FY, Fleming JT, Chiang C (2018) Bergmann glial Sonic hedgehog signaling activity is required for proper cerebellar cortical expansion and architecture. Dev Biol 440:152-166. https:// doi.org/10.1016/j.ydbio.2018.05.015

15. Heng X, Guo Q, Leung AW, Li JY (2017) Analogous mechanism regulating formation of neocortical basal radial glia and cerebellar Bergmann glia. eLife 6:e23253. https://doi.org/10.7554/eLife .23253

16. Sathyamurthy A, Yin D-M, Barik A et al (2015) ERBB3-mediated regulation of Bergmann glia proliferation in cerebellar lamination. Development 142:522-532. https://doi.org/10.1242/ dev.115931

17. Clemente D, Ortega MC, Melero-Jerez C, de Castro F (2013) The effect of glia-glia interactions on oligodendrocyte precursor cell biology during development and in demyelinating diseases. Front Cell Neurosci 7:268. https://doi.org/10.3389/fncel.2013.00268

18. Fogarty MP, Emmenegger BA, Grasfeder LL et al (2007) Fibroblast growth factor blocks Sonic hedgehog signaling in neuronal precursors and tumor cells. Proc Natl Acad Sci USA 104:29732978. https://doi.org/10.1073/pnas.0605770104

19. Poblete-Naredo I, Guillem AM, Juárez C et al (2011) Brainderived neurotrophic factor and its receptors in Bergmann glia cells. Neurochem Int 59:1133-1144. https://doi.org/10.1016/j. neuint.2011.10.002

20. Dunaevsky A (2012) Neuron-glial interactions in the developing cerebellum. Microsc Microanal 18:742-744. https://doi. org/10.1017/S1431927612000256 
21. Ferrini F, De Koninck Y (2013) Microglia control neuronal network excitability via BDNF signalling. Neural Plast 2013:429815. https://doi.org/10.1155/2013/429815

22. Okuda H, Tatsumi K, Morita-Takemura S et al (2016) Hedgehog signaling modulates the release of gliotransmitters from cultured cerebellar astrocytes. Neurochem Res 41:278-289. https://doi. org/10.1007/s11064-015-1791-y

23. Li J, Zhang L, Chu Y et al (2016) Astrocytes in oligodendrocyte lineage development and white matter pathology. Front Cell Neurosci 10:119. https://doi.org/10.3389/fncel.2016.00119

24. Araujo APB, Carpi-Santos R, Gomes FCA (2019) The role of astrocytes in development of the cerebellum. Cerebellum 18(6):1017-1035. https://doi.org/10.1007/s12311-019-01046-0

25. Stiles J, Jernigan TL (2010) The basics of brain development. Neuropsychol Rev 20:327-348. https://doi.org/10.1007/s1106 5-010-9148-4

26. Back SA, Rosenberg PA (2014) Pathophysiology of glia in perinatal white matter injury. Glia 62:1790-1815. https://doi. org/10.1002/glia.22658

27. Benn T, Halfpenny C, Scolding N (2001) Glial cells as targets for cytotoxic immune mediators. Glia 36:200-211

28. Wilson HC, Onischke C, Raine CS (2003) Human oligodendrocyte precursor cells in vitro: phenotypic analysis and differential response to growth factors. Glia 44:153-165. https://doi. org/10.1002/glia.10280

29. Pang Y, Fan L-W, Tien L-T et al (2013) Differential roles of astrocyte and microglia in supporting oligodendrocyte development and myelination in vitro. Brain Behav 3:503-514. https:// doi.org/10.1002/brb3.152

30. Domingues HS, Portugal CC, Socodato R, Relvas JB (2016) Oligodendrocyte, astrocyte, and microglia crosstalk in myelin development, damage, and repair. Front Cell Dev Biol 4:71. https ://doi.org/10.3389/fcell.2016.00071

31. Ashwell K (1991) The distribution of microglia and cell death in the fetal rat forebrain. Brain Res Dev Brain Res 58:1-12

32. Wierzba-Bobrowicz T, Kosno-Kruszewska E, Gwiazda E, Lechowicz W (1998) The comparison of microglia maturation in different structures of the human nervous system. Folia Neuropathol 36:152-160

33. Stowell RD, Wong EL, Batchelor HN, Mendes MS, Lamantia CE, Whitelaw BS, Majewska AK (2018) Cerebellar microglia are dynamically unique and survey Purkinje neurons in vivo. Dev Neurobiol 78(6):627-644. https://doi.org/10.1002/dneu.22572

34. Paolicelli RC, Jawaid A, Henstridge CM et al (2017) TDP-43 depletion in microglia promotes amyloid clearance but also induces synapse loss. Neuron 95:297-308.e6. https://doi. org/10.1016/j.neuron.2017.05.037

35. Schafer DP, Lehrman EK, Kautzman AG et al (2012) Microglia sculpt postnatal neural circuits in an activity and complement-dependent manner. Neuron 74:691-705. https://doi. org/10.1016/j.neuron.2012.03.026

36. Kaur C, Sivakumar V, Zou Z, Ling E-A (2014) Microgliaderived proinflammatory cytokines tumor necrosis factor-alpha and interleukin-1beta induce Purkinje neuronal apoptosis via their receptors in hypoxic neonatal rat brain. Brain Struct Funct 219:151-170. https://doi.org/10.1007/s00429-012-0491-5

37. Marín-Teva JL, Dusart I, Colin C, et al (2004) Microglia promote the death of developing Purkinje cells. Neuron 41:535-547. https ://doi.org/10.1016/S0896-6273(04)00069-8

38. Nakayama H, Abe M, Morimoto C et al (2018) Microglia permit climbing fiber elimination by promoting GABAergic inhibition in the developing cerebellum. Nat Commun 9:2830. https://doi. org/10.1038/s41467-018-05100-z

39. Miller BA, Crum JM, Tovar CA et al (2007) Developmental stage of oligodendrocytes determines their response to activated microglia in vitro. J Neuroinflammation 4:28. https://doi. org/10.1186/1742-2094-4-28

40. Favrais G, van de Looij Y, Fleiss B et al (2011) Systemic inflammation disrupts the developmental program of white matter. Ann Neurol 70:550-565. https://doi.org/10.1002/ana.22489

41. Pinato L, da Silveira C-M, Franco DG et al (2015) Selective protection of the cerebellum against intracerebroventricular LPS is mediated by local melatonin synthesis. Brain Struct Funct 220:827-840. https://doi.org/10.1007/s00429-013-0686-4

42. Bannerman P, Hahn A, Soulika A et al (2007) Astrogliosis in EAE spinal cord: derivation from radial glia, and relationships to oligodendroglia. Glia 55:57-64. https://doi.org/10.1002/ glia.20437

43. Mandolesi G, Gentile A, Musella A, Centonze D (2015) Il-1 $\beta$ dependent cerebellar synaptopathy in a mouse mode of multiple sclerosis. Cerebellum 14:19-22. https://doi.org/10.1007/s1231 1-014-0613-0

44. Matute C, Domercq M, Sánchez-Gómez M-V (2006) Glutamatemediated glial injury: mechanisms and clinical importance. Glia 53:212-224. https://doi.org/10.1002/glia.20275

45. Baltan S (2015) Can lactate serve as an energy substrate for axons in good times and in bad, in sickness and in health? Metab Brain Dis 30:25-30. https://doi.org/10.1007/s11011-014-9595-3

46. Rinholm JE, Hamilton NB, Kessaris N et al (2011) Regulation of oligodendrocyte development and myelination by glucose and lactate. J Neurosci 31:538-548. https://doi.org/10.1523/JNEUR OSCI.3516-10.2011

47. Weber B, Barros LF (2015) The astrocyte: powerhouse and recycling center. Cold Spring Harb Perspect Biol. https://doi. org/10.1101/cshperspect.a020396

48. Xiao J, Wong AW, Willingham MM et al (2010) Brain-derived neurotrophic factor promotes central nervous system myelination via a direct effect upon oligodendrocytes. Neurosignals 18:186202. https://doi.org/10.1159/000323170

49. Vaillant C, Monard D (2009) SHH pathway and cerebellar development. Cerebellum 8:291-301. https://doi.org/10.1007/s1231 1-009-0094-8

50. Káradóttir R, Attwell D (2007) Neurotransmitter receptors in the life and death of oligodendrocytes. Neuroscience 145:14261438. https://doi.org/10.1016/j.neuroscience.2006.08.070

51. Luyt K, Slade TP, Dorward JJ et al (2007) Developing oligodendrocytes express functional GABA(B) receptors that stimulate cell proliferation and migration. J Neurochem 100:822-840. https ://doi.org/10.1111/j.1471-4159.2006.04255.x

52. Shaham S (2005) Glia-neuron interactions in nervous system function and development. Curr Top Dev Biol 69:39-66. https ://doi.org/10.1016/S0070-2153(05)69003-5

53. Kato TA, Watabe M, Kanba S (2013) Neuron-glia interaction as a possible glue to translate the mind-brain gap: a novel multidimensional approach toward psychology and psychiatry. Front Psychiatry 4:139. https://doi.org/10.3389/fpsyt.2013.00139

54. Abbott NJ, Rönnbäck L, Hansson E (2006) Astrocyte-endothelial interactions at the blood-brain barrier. Nat Rev Neurosci 7:4153. https://doi.org/10.1038/nrn1824

55. Molofsky AV, Krencik R, Krenick R et al (2012) Astrocytes and disease: a neurodevelopmental perspective. Genes Dev 26:891907. https://doi.org/10.1101/gad.188326.112

56. Hughes EG, Elmariah SB, Balice-Gordon RJ (2010) Astrocyte secreted proteins selectively increase hippocampal GABAergic axon length, branching, and synaptogenesis. Mol Cell Neurosci 43:136-145. https://doi.org/10.1016/j.mcn.2009.10.004

57. Losi G, Mariotti L, Carmignoto G (2014) GABAergic interneuron to astrocyte signalling: a neglected form of cell communication in the brain. Philos Trans R Soc Lond B 369:20130609. https ://doi.org/10.1098/rstb.2013.0609 
58. Yamada K, Watanabe M (2002) Cytodifferentiation of Bergmann glia and its relationship with Purkinje cells. Anat Sci Int 77:94-108. https://doi.org/10.1046/j.0022-7722.2002.00021.x

59. Dahmane N, Sánchez P, Gitton Y et al (2001) The Sonic Hedgehog-Gli pathway regulates dorsal brain growth and tumorigenesis. Dev Camb Engl 128:5201-5212

60. Horch HW, Katz LC (2002) BDNF release from single cells elicits local dendritic growth in nearby neurons. Nat Neurosci 5:1177-1184. https://doi.org/10.1038/nn927

61. Borghesani PR, Peyrin JM, Klein R et al (2002) BDNF stimulates migration of cerebellar granule cells. Dev Camb Engl 129:1435-1442

62. Bessis A, Béchade C, Bernard D, Roumier A (2007) Microglial control of neuronal death and synaptic properties. Glia 55:233238. https://doi.org/10.1002/glia.20459

63. Polazzi E, Gianni T, Contestabile A (2001) Microglial cells protect cerebellar granule neurons from apoptosis: evidence for reciprocal signaling. Glia 36:271-280

64. Ishibashi K, Miura Y, Toyohara J et al (2019) Unchanged type 1 metabotropic glutamate receptor availability in patients with Alzheimer's disease: a study using 11C-ITMM positron emission tomography. NeuroImage Clin 22:101783. https://doi. org/10.1016/j.nicl.2019.101783

65. Kuhn SA, van Landeghem FKH, Zacharias R et al (2004) Microglia express $\mathrm{GABA}(\mathrm{B})$ receptors to modulate interleukin release. Mol Cell Neurosci 25:312-322. https://doi.org/10.1016/j. men.2003.10.023

66. Baumann N, Pham-Dinh D (2001) Biology of oligodendrocyte and myelin in the mammalian central nervous system. Physiol Rev 81:871-927

67. Mensch S, Baraban M, Almeida R et al (2015) Synaptic vesicle release regulates myelin sheath number of individual oligodendrocytes in vivo. Nat Neurosci 18:628-630. https://doi. org/10.1038/nn.3991

68. Stassart RM, Möbius W, Nave K-A, Edgar JM (2018) The axonmyelin unit in development and degenerative disease. Front Neurosci 12:467. https://doi.org/10.3389/fnins.2018.00467

69. Lee Y, Morrison BM, Li Y et al (2012) Oligodendroglia metabolically support axons and contribute to neurodegeneration. Nature 487:443-448. https://doi.org/10.1038/nature11314

70. Fröhlich N, Nagy B, Hovhannisyan A, Kukley M (2011) Fate of neuron-glia synapses during proliferation and differentiation of NG2 cells. J Anat 219:18-32. https://doi.org/10.111 1/j.1469-7580.2011.01392.x

71. Li C, Xiao L, Liu X et al (2013) A functional role of NMDA receptor in regulating the differentiation of oligodendrocyte precursor cells and remyelination. Glia 61:732-749. https://doi. org/10.1002/glia.22469

72. Arellano RO, Sánchez-Gómez MV, Alberdi E et al (2016) Axon-to-glia interaction regulates GABAA receptor expression in oligodendrocytes. Mol Pharmacol 89:63-74. https://doi. org $/ 10.1124 / \mathrm{mol} .115 .100594$

73. Zonouzi M, Scafidi J, Li P et al (2015) GABAergic regulation of cerebellar NG2 cell development is altered in perinatal white matter injury. Nat Neurosci 18:674-682. https://doi.org/10.1038/ nn. 3990

74. Vélez-Fort M, Maldonado PP, Butt AM et al (2010) Postnatal switch from synaptic to extrasynaptic transmission between interneurons and NG2 cells. J Neurosci 30:6921-6929. https:// doi.org/10.1523/JNEUROSCI.0238-10.2010

75. Collin L, Doretto S, Malerba M et al (2007) Oligodendrocyte ablation affects the coordinated interaction between granule and Purkinje neurons during cerebellum development. Exp Cell Res 313:2946-2957. https://doi.org/10.1016/j.yexcr.2007.05.003
76. Revuelta M, Elicegui A, Moreno-Cugnon L et al (2019) Ischemic stroke in neonatal and adult astrocytes. Mech Ageing Dev 183:111147. https://doi.org/10.1016/j.mad.2019.111147

77. Itoh N, Itoh Y, Tassoni A, Ren E, Kaito M, Ohno A, Ao Y, Farkhondeh V, Johnsonbaugh H, Burda J, Sofroniew MV, Voskuhl RR (2017) Cell-specific and region-specific transcriptomics in the multiple sclerosis model: focus on astrocytes. Proc Natl Acad Sci USA. https://doi.org/10.1073/pnas.1716032115

78. Brambilla R (2019) The contribution of astrocytes to the neuroinflammatory response in multiple sclerosis and experimental autoimmune encephalomyelitis. Acta Neuropathol 137(5):757-783. https://doi.org/10.1007/s00401-019-01980-7

79. Ikeshima-Kataoka H, Abe Y, Abe T, Yasui M (2013) Immunological function of aquaporin-4 in stab-wounded mouse brain in concert with a pro-inflammatory cytokine inducer, osteopontin. Mol Cell Neurosci 56:65-75. https://doi.org/10.1016/j. men.2013.02.002

80. Cekanaviciute E, Fathali N, Doyle KP et al (2014) Astrocytic transforming growth factor-beta signaling reduces subacute neuroinflammation after stroke in mice: astrocytic TGF $\beta$ reduces neuroinflammation. Glia 62:1227-1240. https://doi. org/10.1002/glia.22675

81. Liu Z, Chopp M (2016) Astrocytes, therapeutic targets for neuroprotection and neurorestoration in ischemic stroke. Prog Neurobiol 144:103-120. https://doi.org/10.1016/j.pneur obio.2015.09.008

82. Amiry-Moghaddam M, Williamson A, Palomba M et al (2003) Delayed K+ clearance associated with aquaporin-4 mislocalization: phenotypic defects in brains of alpha-syntrophin-null mice. Proc Natl Acad Sci USA 100:13615-13620. https://doi. org/10.1073/pnas.2336064100

83. Kutzelnigg A, Faber-Rod JC, Bauer J, Lucchinetti CF, Sorensen PS, Laursen H, Stadelmann C, Brück W, Rauschka H, Schmidbauer M, Lassmann H (2007) Widespread demyelination in the cerebellar cortex in multiple sclerosis. Brain Pathol 17(1):3844. https://doi.org/10.1111/j.1750-3639.2006.00041.x

84. Tornes L, Conway B, Sheremata W (2014) Multiple Sclerosis and the cerebellum. Neurol Clin 32:957-977. https://doi. org/10.1016/j.ncl.2014.08.001

85. Wilkins A (2017) Cerebellar dysfunction in multiple sclerosis. Front Neurol 8:312. https://doi.org/10.3389/fneur.2017.00312

86. Brosnan CF, Raine CS (2013) The astrocyte in multiple sclerosis revisited. Glia 61:453-465. https://doi.org/10.1002/ glia. 22443

87. Ludwin SK, Rao VT, Moore CS, Antel JP (2016) Astrocytes in multiple sclerosis. Mult Scler J 22:1114-1124. https://doi. org/10.1177/1352458516643396

88. Burm SM, Peferoen LAN, Zuiderwijk-Sick EA et al (2016) Expression of IL-1 $\beta$ in rhesus EAE and MS lesions is mainly induced in the CNS itself. J Neuroinflammation 13:138. https:// doi.org/10.1186/s12974-016-0605-8

89. Musella A, Mandolesi G, Gentile A et al (2013) Cladribine interferes with IL-1 $\beta$ synaptic effects in experimental multiple sclerosis. J Neuroimmunol 264:8-13. https://doi.org/10.1016/j. jneuroim.2013.08.009

90. Xie D, Shen F, He S et al (2016) IL-1 $\beta$ induces hypomyelination in the periventricular white matter through inhibition of oligodendrocyte progenitor cell maturation via FYN/MEK/ERK signaling pathway in septic neonatal rats: IL- $1 \beta$ and periventricular white matter damage. Glia 64:583-602. https://doi.org/10.1002/ glia. 22950

91. Kocur M, Schneider R, Pulm A-K et al (2015) IFN $\beta$ secreted by microglia mediates clearance of myelin debris in CNS autoimmunity. Acta Neuropathol Commun 3:20. https://doi. org/10.1186/s40478-015-0192-4 
92. Río J, Rovira À, Tintoré M et al (2008) Relationship between MRI lesion activity and response to IFN- $\beta$ in relapsing-remitting multiple sclerosis patients. Mult Scler J 14:479-484. https://doi. org/10.1177/1352458507085555

93. Scheu S, Ali S, Mann-Nüttel R et al (2019) Interferon $\beta$-mediated protective functions of microglia in central nervous system autoimmunity. Int J Mol Sci 20:190. https://doi.org/10.3390/ijms2 0010190

94. di Penta A, Moreno B, Reix S et al (2013) Oxidative stress and proinflammatory cytokines contribute to demyelination and axonal damage in a cerebellar culture model of neuroinflammation. PLoS ONE 8:e54722. https://doi.org/10.1371/journ al.pone. 0054722

95. de Silva RN, Vallortigara J, Greenfield J et al (2019) Diagnosis and management of progressive ataxia in adults. Pract Neurol 19:196-207. https://doi.org/10.1136/practneurol-2018-002096

96. The spinocerebellar ataxias-UpToDate (2019) https://www. uptodate.com/contents/the-spinocerebellar-ataxias?search=thespinocerebellar-ataxias.\&source $=$ search_result\&selectedTi tle $=1 \sim 33 \&$ usage_type $=$ default $\&$ display_rank $=1$. Accessed 30 Sep 2019

97. Ferro A, Qu W, Lukowicz A et al (2018) Inhibition of NF-кB signaling in IKK $\beta \mathrm{F} / \mathrm{F}$;LysM Cre mice causes motor deficits but does not alter pathogenesis of Spinocerebellar ataxia type 1. PLoS ONE 13:e0200013. https://doi.org/10.1371/journ al.pone. 0200013

98. Cvetanovic M, Ingram M, Orr H, Opal P (2015) Early activation of microglia and astrocytes in mouse models of spinocerebellar ataxia type 1. Neuroscience 289:289-299. https://doi. org/10.1016/j.neuroscience.2015.01.003

99. Kim JH, Lukowicz A, Qu W et al (2018) Astroglia contribute to the pathogenesis of spinocerebellar ataxia type 1 (SCA1) in a biphasic, stage-of-disease specific manner. Glia 66:1972-1987. https://doi.org/10.1002/glia.23451

100. Evers MM, Tran H-D, Zalachoras I et al (2013) Ataxin-3 protein modification as a treatment strategy for spinocerebellar ataxia type 3: removal of the CAG containing exon. Neurobiol Dis 58:49-56. https://doi.org/10.1016/j.nbd.2013.04.019

101. McLoughlin HS, Moore LR, Chopra R et al (2018) Oligonucleotide therapy mitigates disease in spinocerebellar ataxia type 3 mice. Ann Neurol 84:64-77. https://doi.org/10.1002/ana.25264

102. Hanaie R, Mohri I, Kagitani-Shimono K et al (2018) Aberrant cerebellar-cerebral functional connectivity in children and adolescents with autism spectrum disorder. Front Hum Neurosci 12:454. https://doi.org/10.3389/fnhum.2018.00454

103. D'Mello AM, Stoodley CJ (2015) Cerebro-cerebellar circuits in autism spectrum disorder. Front Neurosci 9:408. https://doi. org/10.3389/fnins.2015.00408

104. Pardo CA, Farmer CA, Thurm A et al (2017) Serum and cerebrospinal fluid immune mediators in children with autistic disorder: a longitudinal study. Mol Autism 8:1. https://doi.org/10.1186/ s13229-016-0115-7

105. Dawson G, Sun JM, Davlantis KS et al (2017) Autologous cord blood infusions are safe and feasible in young children with autism spectrum disorder: results of a single-center phase I open-label trial. Stem Cells Transl Med 6:1332-1339. https:// doi.org/10.1002/sctm.16-0474

106. Riordan NH, Hincapié ML, Morales I et al (2019) Allogeneic human umbilical cord mesenchymal stem cells for the treatment of autism spectrum disorder in children: safety profile and effect on cytokine levels. Stem Cells Transl Med. https://doi. org/10.1002/sctm.19-0010

107. Custer SK, Garden GA, Gill N et al (2006) Bergmann glia expression of polyglutamine-expanded ataxin-7 produces neurodegeneration by impairing glutamate transport. Nat Neurosci 9:1302-1311. https://doi.org/10.1038/nn1750
108. Nagamitsu S, Yamashita Y, Tanigawa H et al (2015) Upregulated GABA inhibitory function in ADHD children with child behavior checklist-dysregulation profile: 123I-iomazenil SPECT study. Front Psychiatry 6:84. https://doi.org/10.3389/fpsyt.2015.00084

109. Chen L, Huang X, Lei D et al (2015) Microstructural abnormalities of the brain white matter in attention-deficit/hyperactivity disorder. J Psychiatry Neurosci 40:280-287

110. Ishibashi M, Egawa K, Fukuda A (2019) Diverse actions of astrocytes in GABAergic signaling. Int J Mol Sci. https://doi. org/10.3390/ijms20122964

111. Kim YS, Woo J, Lee CJ, Yoon B-E (2017) Decreased glial GABA and tonic inhibition in cerebellum of mouse model for attention-deficit/hyperactivity disorder (ADHD). Exp Neurobiol 26:206-212. https://doi.org/10.5607/en.2017.26.4.206

112. Garden GA, La Spada AR (2008) Molecular pathogenesis and cellular pathology of spinocerebellar ataxia type 7 neurodegeneration. Cereb Lond Engl 7:138-149. https://doi.org/10.1007/ s12311-008-0027-y

113. Schmitz T, Krabbe G, Weikert G et al (2014) Minocycline protects the immature white matter against hyperoxia. Exp Neurol 254:153-165. https://doi.org/10.1016/j.expneurol.2014.01.017

114. Ma DQ, Whitehead PL, Menold MM et al (2005) Identification of significant association and gene-gene interaction of GABA receptor subunit genes in autism. Am J Hum Genet 77:377-388. https://doi.org/10.1086/433195

115. Zhou P, Qian L, Zhou T, Iadecola C (2005) Mitochondria are involved in the neurogenic neuroprotection conferred by stimulation of cerebellar fastigial nucleus. J Neurochem 95:221-229. https://doi.org/10.1111/j.1471-4159.2005.03358.x

116. Beppu K, Sasaki T, Tanaka KF et al (2014) Optogenetic countering of glial acidosis suppresses glial glutamate release and ischemic brain damage. Neuron 81:314-320. https://doi. org/10.1016/j.neuron.2013.11.011

117. Helleringer R, Chever O, Daniel H, Galante M (2017) Oxygen and glucose deprivation induces bergmann glia membrane depolarization and $\mathrm{Ca} 2+$ rises mainly mediated by $\mathrm{K}+$ and ATP increases in the extracellular space. Front Cell Neurosci 11:349. https://doi.org/10.3389/fncel.2017.00349

118. Scheuer T, Brockmöller V, Blanco Knowlton M et al (2015) Oligodendroglial maldevelopment in the cerebellum after postnatal hyperoxia and its prevention by minocycline. Glia 63:1825-1839. https://doi.org/10.1002/glia.22847

119. Borges CG, Canani CR, Fernandes CG et al (2015) Reactive nitrogen species mediate oxidative stress and astrogliosis provoked by in vivo administration of phytanic acid in cerebellum of adolescent rats: a potential contributing pathomechanism of cerebellar injury in peroxisomal disorders. Neuroscience 304:122132. https://doi.org/10.1016/j.neuroscience.2015.07.028

120. Jablonska B, Scafidi J, Aguirre A et al (2012) Oligodendrocyte regeneration after neonatal hypoxia requires FoxO1-mediated p27Kip1 expression. J Neurosci 32:14775-14793. https://doi. org/10.1523/JNEUROSCI.2060-12.2012

121. Kim DW, Shin MJ, Choi YJ et al (2018) Tat-ATOX1 inhibits inflammatory responses via regulation of MAPK and NF- $\mathrm{KB}$ pathways. BMB Rep 51:654-659

122. Arvin KL, Han BH, Du Y et al (2002) Minocycline markedly protects the neonatal brain against hypoxic-ischemic injury. Ann Neurol 52:54-61. https://doi.org/10.1002/ana.10242

123. Cai Z, Lin S, Fan L-W et al (2006) Minocycline alleviates hypoxic-ischemic injury to developing oligodendrocytes in the neonatal rat brain. Neuroscience 137:425-435. https://doi. org/10.1016/j.neuroscience.2005.09.023

124. Tang M, Alexander H, Clark RSB et al (2010) Minocycline reduces neuronal death and attenuates microglial response after pediatric asphyxial cardiac arrest. J Cereb Blood Flow Metab 30:119-129. https://doi.org/10.1038/jcbfm.2009.194 
125. Cai Z-Y, Yan Y, Chen R (2010) Minocycline reduces astrocytic reactivation and neuroinflammation in the hippocampus of a vascular cognitive impairment rat model. Neurosci Bull 26:28-36. https://doi.org/10.1007/s12264-010-0818-2

126. Ueno M, Fujita Y, Tanaka T et al (2013) Layer V cortical neurons require microglial support for survival during postnatal development. Nat Neurosci 16:543-551. https://doi.org/10.1038/nn.3358

127. Tsuji M, Wilson MA, Lange MS, Johnston MV (2004) Minocycline worsens hypoxic-ischemic brain injury in a neonatal mouse model. Exp Neurol 189:58-65. https://doi.org/10.1016/j.expne urol.2004.01.011

128. Xue M, Mikliaeva EI, Casha S et al (2010) Improving outcomes of neuroprotection by minocycline: guides from cell culture and intracerebral hemorrhage in mice. Am J Pathol 176:1193-1202. https://doi.org/10.2353/ajpath.2010.090361

129. Lewerenz J, Maher P (2015) Chronic glutamate toxicity in neurodegenerative diseases: what is the evidence? Front Neurosci 9:469. https://doi.org/10.3389/fnins.2015.00469

130. Juravleva E, Barbakadze T, Mikeladze D, Kekelidze T (2005) Creatine enhances survival of glutamate-treated neuronal/glial cells, modulates Ras/NF-kappaB signaling, and increases the generation of reactive oxygen species. J Neurosci Res 79:224230. https://doi.org/10.1002/jnr.20291

131. Augusto RL, Isaac AR, da Silva-Júnior II et al (2017) Fighting oxidative stress: increased resistance of male rat cerebellum at weaning induced by low omega 6/omega 3 ratio in a protein-deficient diet. Cereb Lond Engl 16:103-117. https://doi.org/10.1007/ s12311-016-0773-1

132. Kaur P, Heggland I, Aschner M, Syversen T (2008) Docosahexaenoic acid may act as a neuroprotector for methylmercury-induced neurotoxicity in primary neural cell cultures. Neurotoxicology 29:978-987. https://doi.org/10.1016/j.neuro.2008.06.004

133. Manes M, Alberici A, Di Gregorio E et al (2019) Long-term efficacy of docosahexaenoic acid (DHA) for spinocerebellar ataxia 38 (SCA38) treatment: an open label extension study. Parkinsonism Relat Disord 63:191-194. https://doi.org/10.1016/j.parkr eldis.2019.02.040

134. Scheuer T, Sharkovska Y, Tarabykin V et al (2018) Neonatal hyperoxia perturbs neuronal development in the cerebellum. Mol Neurobiol 55:3901-3915. https://doi.org/10.1007/s1203 5-017-0612-5

135. Scafidi J, Hammond TR, Scafidi S et al (2014) Intranasal epidermal growth factor treatment rescues neonatal brain injury. Nature 506:230-234. https://doi.org/10.1038/nature12880

136. Obata K, Hirono M, Kume N et al (2008) GABA and synaptic inhibition of mouse cerebellum lacking glutamate decarboxylase 67. Biochem Biophys Res Commun 370:429-433. https://doi. org/10.1016/j.bbrc.2008.03.110

137. Woo J, Min JO, Kang D-S et al (2018) Control of motor coordination by astrocytic tonic GABA release through modulation of excitation/inhibition balance in cerebellum. Proc Natl Acad Sci USA 115:5004-5009. https://doi.org/10.1073/pnas.1721187115

Publisher's Note Springer Nature remains neutral with regard to jurisdictional claims in published maps and institutional affiliations. 